\title{
Soil biodiversity and environmental change in European forests
}

\author{
Martin Lukac \\ School of Agriculture, Policy and Development, University of Reading, RG6 6AR, United Kingdom \\ Czech University of Life Sciences Prague, Faculty of Forestry and Wood Sciences, Kamýcká 129 \\ CZ-165 21 Praha 6-Suchdol, Czech Republic
}

\begin{abstract}
Biodiversity not only responds to environmental change, but has been shown to be one of the key drivers of ecosystem function and service delivery. Forest soil biodiversity is also governed by these principles, the structure of soil biological communities is clearly determined by spatial, temporal and hierarchical factors. Global environmental change, together with land-use change and forest ecosystem management, impacts the aboveground structure and composition of European forests. Due to the close link between the above- and belowground parts of forest ecosystems, we know that soil biodiversity is also impacted. However, very little is known about the nature of these impacts; effects they have on the overall level of biodiversity, the functions it fulfills, and on the future stability of forests and forest soils. Even though much remains to be learned about the relationships between soil biodiversity and forest ecosystem functionality, it is clear that better effort needs to be made to preserve existing soil biodiversity and forest conservation strategies taking soils into account must be considered.
\end{abstract}

Key words: forest soils; community structure; ecosystem function; conservation

Editor: Erika Gömöryová

\section{Introduction}

Aboveground, sustained research effort has shown that biodiversity - whether that of species, guilds, functional traits or even genes - has a strong and positive relationship with ecosystem productivity (Worm \& Duffy 2003) and that this relationship is valid across a range of ecosystems, including forests. At the same time, recent and accelerating loss of biodiversity may be linked to a reduction of ecosystem productivity as well as other functions, but also ecosystem stability, resilience and productivity (Cardinale et al. 2012). Past decades have witnessed an explosion of experimental and theoretical research effort aimed at understanding the role of biodiversity in the myriad of ecosystems on Earth. Due to the obvious advantage of being able to see it, the vast majority of studies and conceptual developments in terrestrial systems have focused on the aboveground part. Repeated and replicated manipulation experiments have shown that ecosystem function and biodiversity are intrinsically linked - at least aboveground (Grime 1997; Oliver et al. 2015; Schulze \& Mooney 1994). However, low accessibility of forest ecosystems and their long life cycles, coupled with laboriousness of soil research have hindered experimentation and thus our understanding of the contribution of the diversity of forest soil biota to ecosystem function. Our knowledge of the contribution of belowground biodiversity to overall ecosystem function is some way behind that for the visible part, despite the implied functional connection between the two. This lack of knowledge limits our ability to harness belowground biodiversity to deliver functions in the here-and-now and to predict its capacity to continue delivering in the future (Bardgett \& Van Der Putten 2014).

\section{Soil biodiversity and its organisation}

Soil is the largest reservoir of biodiversity on Earth, one gram of soil has been shown to contain over 1 billion individual bacterial cells representing a large community of tens of thousands of species (Decaëns 2010), the identity, biology and function of many of these are completely unknown at present and may never be fully understood. Soil biodiversity however encompasses many other organism types besides bacteria; there are fungi, nematodes, earthworms, arthropods and even mammals who complete at least part of their life cycle in the soil and thus contribute to the overall soil biodiversity. One thing all of these life forms have in common is the fact that they 
all depend on aboveground primary production as their ultimate source of energy (Wardle et al. 2004). In forest ecosystems, organic matter rich in carbohydrates is either deposited on the soil surface or released into the soil profile from live and dead tree roots. A long chain of soil-dwelling organisms then utilizes energy contained in organic matter to power their metabolism, growth and reproduction. Soil food web is also the main driving engine of nutrient acquisition and recycling in forest ecosystems, many of which would be unable to exist without the functional contribution of soil biota (Fischer et al. 2006). The dependence on aboveground primary productivity, together with the seasonal nature of organic matter input, leads to spatial, temporal and hierarchical arrangement of soil biodiversity. Correct understanding of the contribution of soil biodiversity to soil function thus implies knowledge of the input of each species, its variation in space and in time and the interactions between species and communities of organisms.

Recent developments and decreasing cost of molecular methods have led to the creation of a growing collection of evidence documenting the level of species diversity present in many soils on Earth, together with the identification and description of species performing key functions. Long-standing assumptions guiding our approach to spatial distribution of soil biodiversity at global or biome scales - that any soil organism has the capacity to inhabit all soils - may not have been correct; it is now clear that soil organisms are spatially distributed and do not have the capacity to inhabit any soil (Callaway \& Maron 2006). Global distribution of soil-dwelling species is restricted, probably by a combination of climatic, soil and plant composition factors (Öpik et al. 2006; Tedersoo et al. 2012), an observation especially relevant for forest ecosystems given the long life cycle of the dominant form of vegetation which tends to dictate many ecosystem characteristics. Since the life span of nearly all soil organisms is an order of magnitude shorter than that of trees, it is likely that soil biodiversity 'acclimates' to tree species identity and diversity. Spatial distribution of soil biodiversity is clearly linked to soil organism size, which ranges from single micrometres for bacteria, to tens of centimetres for earthworms, to several hectares for some soil fungi - a specimen of Armillaria solidipes covering an area of about $10 \mathrm{~km}^{2}$ in the Malheur National Forest in Oregon (USA) is thought to be the largest organism on Earth (Richardson Dodge 2000). At the smallest scale, the distribution of soil biota is governed by soil structure which determines resource availability (Elliott 1986; Rasche et al. 2011). Biotic interactions such as competition and predation, root exudation by trees, turning-over of soil by larger organisms also play a part, mainly by affecting chemical composition of soil solution and thus speeding up or slowing down growth of microbial populations (Langenheder \& Prosser 2008; Stark \& Firestone 1995). At centimetre to metre scale, diversity of soil biota is affected by local variation of soil conditions such as texture, organic matter content and water holding capacity (Wardle et al. 2004), which tends to be rather high in forest soils due to the often rugged nature of the terrain where most European forest are. Finally, at ecosystem level, spatial patterns of soil biodiversity are governed by topography and related climatic factors, disturbance regime and landscape connectivity (Fierer \& Jackson 2006; Reinhart \& Callaway 2006). As a result, spatial distribution of forest soil biodiversity is fragmented, as is our understanding of its function which is largely dependent on the body size of the organism as larger species tend to be better studied.

Analogous to the factors affecting spatial distribution, temporal changes in the diversity of soil organisms are very much dependent on the size of the organism in question. Population size of species with the smallest body size is usually governed by minute availability of resources such as water, nutrients and oxygen. An increase of water content in dry soil or a nutrient availability pulse can cause a rapid response of microbial populations (Austin et al. 2004), fast multiplication of single cell organisms drives an increase in population size. Nutrient pulses may be both biotic or abiotic in nature, exudation by tree roots has been shown to trigger growth of specific groups of microorganisms at the expense of others (Bais et al. 2006; El Zahar Haichar et al. 2008) - a clear example of an interaction between above- and belowground diversity. Temporal changes in microbial community composition at the smallest scale can take minutes to hours and are usually accompanied by a rapid change of the dominant function performed by microbes at their location. Longer-term fluctuation of resource availability over seasons or years, however, affects soil biodiversity at all levels (Lauber et al. 2013). The main reason for this effect is the fact that all are dependent on aboveground productivity as their energy source-aboveground seasonality must find its reflection belowground. At present, we have only a very fragmented picture of this relationship, there is some evidence that microbial communities undergo a complete turnover from winter to summer (Hamel et al. 2006), are differentially affected by seasonal resource availability and that changes in plant community exert strong influence over the composition of soil biota. The latter factor might be of critical importance in forest ecosystems, especially in the case of conversion of natural forests to plantations or restocking of stands with the view of increasing their climate change resilience. At the largest temporal scaleand the one currently least supported by evidence- there is an indication that specific communities inhabit soils at different stages of natural succession or post-disturbance recovery (Neutel et al. 2002).

Vast numbers on individuals, large variation in body size and often rather constricted specialisation in the food source or life strategy of soil biota, gives rise to a range of complex hierarchical arrangements of communities within forest soils. The simplest soil food-webs may con- 
sist of heterotrophic, nitrogen-fixing and autotrophic photosynthesising bacteria, with little reliance on plant productivity (Mikola \& Setälä 1998). However, with any increase of aboveground productivity comes an influx of different soil-inhabiting life forms which self-organise into communities performing a variety of functions such as organic matter fragmentation, element cycling or water uptake. Over time, and in an absence of disturbance, such communities become more and more complex by increasing food-chain length, accumulating larger levels of biodiversity and attaining higher level of stability (Neutel et al. 2007; Rooney et al. 2006). The mechanics of the relationship between complexity and stability of function of forest soil biological communities is not clear. However, it is becoming evident that soil biodiversity might have direct implications for forest ecosystem stability, for example under environmental change (Isbell et al. 2015). Much is known about individual functions performed by specific groups of organisms, but our knowledge of how widely functions are distributes among species within those groups is far from complete. Thus, assigning an estimate of redundancy to any given species within a community is fraught with difficulty - changes in species composition may or may not translate to changes in function (Strickland et al. 2009).

\section{Forest soil biodiversity and ecosystem function}

Forest soil biodiversity is considered to be the driving engine of soil based ecosystem services such as aboveground primary production, nutrient cycling, carbon sequestration and water purification (Turbé et al. 2010). As already mentioned, our understanding of the relationship between biodiversity, ecosystem functions and services in forest ecosystems is rapidly improving, although most of current research on biodiversity-ecosystem functioning in the forests still focuses on aboveground part of forest ecosystems. European forests are expected to play a large role in future provision of ecosystem services that underpin continuous existence of human society and contribute to climate change mitigation (e.g. (García-Nieto et al. 2013; Schröter et al. 2005) and it is clear that the soil ecosystem is an integral and essential component of this process. With particular reference to ecosystem functions supported by soil biota, the marked difference in framing socio-economic perspectives on biodiversity between agriculture and forestry must be pointed out (Mori et al. 2017). Many currently promoted agricultural practices focus specifically o soils and the maintenance of their productive functions, with increasing realization that it is the biological component that guarantees soil productivity (Foley et al. 2011). There is no equivalent of this approach for forestry, current forest management or conservation practice considers soil an in situ resource which somehow delivers functions but can be treated as a 'black box'. This means that we are unable to assess the trade-offs among different soil biodiversity levels and multiple ecosystem services they deliver. However, a number of studies linking biodiversity (e.g. genetic, functional) to ecosystem function (e.g. nitrogen fixation, phosphorus mining, organic matter decomposition, soil structure formation) have revealed that biodiversity promotes functionality and thus supports a range of ecosystem services (e.g. tree growth, forest fruit production, climate regulation, water filtration; Cardinale 2012). This is especially true for forests, which are characterized by higher structural complexity, longer life cycles of the dominant taxa and larger-scale spatiotemporal dynamics (Scherer-Lorenzen 2014). Humanity's need to preserve ecosystem productivity and resilience thus brings us to the issue of preserving soil biodiversity. Land-use changes affected by humans, being it complete deforestation or just a change of tree species in a forest stand, invariably introduce some level of physical and chemical soil disturbance, which usually interferes with soil biota and the processes it supports (Altieri 1999). One of the most striking effects of human land-use is simplification of soil biological communities and thus a decrease in soil biodiversity (Giller et al. 1997). Ecosystem functions delivered by soil biota will inevitably be impaired as soil biodiversity underpinning each and every function is reduced. Reduction of diversity will negatively impact the resilience of soil biological communities in terms of supporting soil functions under changing environmental conditions (Folke et al. 2004). Less diverse communities will contain fewer redundant species which may have the capacity to sustain soil functions under a new set of conditions. Even when starting from a position where a single 3 -dimentional soil profile may contain more biodiversity than the entire aboveground ecosystem (Myers et al. 2000), gradual and continuing reduction of soil biodiversity may lead to eventual loss of function.

\section{Forest ecosystem stability and environmental change}

Human activity is the driving factor behind global environmental change we are experiencing at present. Although the exact onset of Anthropocene has not been determined yet (Smith \& Zeder 2013), it is apparent that world's ecosystems are facing a period of rapid change. It is also clear, that high levels of biodiversity in all of its forms are essential for maintaining and safeguarding ecosystem function at this time. Biodiversity has been linked to fundamental ecosystem functionality and is known to contribute to the maintenance of resilience in ecosystems (Elmqvist et al. 2003). Forest ecosystem stability, or resilience, can be defined as the capacity of a system to absorb changes and to maintain fundamental controls on its function and structure (Curran 2011). Forest ecosystem structure is most often perceived in terms 
of the 3-dimentional aboveground structure generated by trees and ground vegetation, however this accepted view completely ignores the spatial and temporal structure of subterranean hierarchies of soil organisms. Biodiversity of the latter might be just as important determinant of ecosystem resilience as the aboveground part. When facing uncertainty, unpredictability, nonlinearity and changeability of conditions, surely the overall diversity and structure of a forest ecosystem must be taken into account. It is also painfully clear, however, that currently we do not have a fit-for-purpose concept of forest resilience thinking that includes soil biodiversity, nor do we know how to apply this type of thinking to forest management.

The overriding issue of forest ecosystem resilience is how to secure the fundamental functionality of the whole and its constituent parts. The insurance hypothesis (Yachi \& Loreau 1999) predicts that ecosystem function is maintained and stabilized in communities where higher redundancy of species is guaranteed by higher species diversity. Many species fulfill the same function and thus reduce suboptimal delivery of that function across space and time. For example, in a soil with several species of saprophytic fungi all competing for the same food resource, should one taxon disappear due to its sensitivity to environmental change, others will continue to fulfill its function and contribute to overall ecosystem stability. Conversely, if diversity is reduced, a fundamental control on ecosystem function in the face of environmental change may be lost from soil communities (Elmqvist et al. 2003).

To date, little is known about the contribution of forest soil biodiversity to overall ecosystem stability. A growing chorus of alarms calls for the investigation of anthropogenic impacts on forest biodiversity (Newbold et al. 2014; Wilcove et al. 2013); land-use change associated with deforestation, forest degradation or tree species replacement in plantations have threatened forestdependent taxa across many regions. The knowledge of impacts of land-use change of soil dwelling organisms dependent on specific tree communities is however still in its infancy. Some inference can be drawn from studies carried out in grassland or agricultural ecosystems, there is some evidence to suggest that the commonly observed relationship between diversity and stability are applicable to forests, but the underlying mechanisms are not necessarily the same (Mori et al. 2017). We thus face a situation where we need to manage the survival and functionality of forest ecosystems (i) without having full understanding of the relationship between biodiversity and resilience and (ii) without having a working description of forest soil biodiversity and all its functions. Some modeling studies explore the implications of rapid environmental change for forest ecosystem service delivery; Duveneck \& Scheller (2015) advocate a climate-suitable planting regime in which tree species from outside their current distribution are planted to anticipate a northward shift. Needless to say, the study does not take any account of soil biodiversity which will need to support the new tree species and maintain ecosystem function under new conditions. We have learnt that global patterns of soil biodiversity are determined by several factors and that forest soil communities acclimate to local conditions which include tree species (Callaway \& Maron 2006). Clearly, with specific regard to soil communities and their diversity, there is a need to broaden the scope of assisted migration and perhaps to explore the possibility and limitation of assisted evolution of forest communities.

\section{Forest conservation and soil biodiversity}

Biodiversity conservation has traditionally focused on the preservation of a small subset of species present in an ecosystem, most often on species perceived as iconic of keystone in that ecosystem (Mace et al. 2012). This approach has been proved as suboptimal, improved knowledge of biodiversity and its role in ecosystem function has shown that it is the ecosystem functions and services (often epitomized as habitats) that should be the focus of conservation effort as their preservation aids the survival of individual species. Reflecting soil biodiversity distribution, both spatial and temporal aspects of forest conservation must be considered. Effects of soil biodiversity on the functionality and stability of forest ecosystem function are spatially constrained and are especially significant at local scale (Pasari et al. 2013). In a human-modified landscape such as that of Europe, the connectivity and heterogeneity of forest habitat patches containing levels of soil biodiversity correspondent to those of natural forests are the key determinant of ecosystem resilience at landscape scale (Standish et al. 2014). A diverse patchwork of structurally complex forest stands connected by corridors can maintain and safeguard higher levels of biodiversity that may increase forest ecosystem resilience to disturbance (Fischer et al. 2006). Higher above- and belowground biodiversity is likely to foster faster postdisturbance recovery from remnant patches of surviving trees or to contain an assembly of species suitable to build an alternative stable state. The capacity of soil biota to travel across landscape and to colonise new habitats obviously varies with organism type and size, however it is unlikely to match tree species movement during assisted migration, only highlighting the need for close scrutiny of suitability between 'resident' soil biota and tree species.

Having considered the spatial aspect of conservation od soil biodiversity, the question of temporal continuity of forest cover deserves equal importance. Forest soil biota is fully dependent on forest primary productivity for all of its energy needs, any discontinuation of forest cover will thus affect availability of carbohydrates and impact soil biodiversity at various levels. Of course, forest soils have evolved in the presence of disturbance which repeatedly discontinues food supply to soil webs and thus have an inherent level of resilience. It is recognized that anthropocene, with its multiple pressures on soil 
biological functioning (climate change, pollution, lowering of tree species diversity or complete replacement, shorter rotations), may lead to critical changes in soil biodiversity which will eventually impact soil function (Folke et al. 2004). Thus, reduced-impact logging and retention forestry is becoming popular across a range of managed forest ecosystems (Lindenmayer et al. 2012). Both approaches aim to preserve key structural elements of a forest stand during harvesting to preserve the continuity of forest cover which his beneficial to biodiversity (Fedrowitz et al. 2014). One benefit of this approach is the continuity of several factors affecting soil condition and thus the survival of forest soil biological community. Maintaining (soil) ecosystem function over time will positively affect the delivery of ecosystem services by European forests. However, despite the recent rise in the popularity of multifunctional forestry, rigorous ecological and socio-economic evaluation of the costs and the benefits associated with reduced-impact logging and retention forestry for biodiversity conservation are still scarce (Messier et al. 2015).

\section{Conclusion}

Agrowing body of scientific evidence indicates that biodiversity not only responds to environmental changes, but that it is a key determinant of a multitude of ecosystem functions and services that are of crucial importance to the survival of human society. This paper has argued that forest soil biodiversity represents a key asset in the human 'environmental portfolio', albeit one about which little is known. It is clear that soil biology drives and regulates key ecosystem functions in forests and that ongoing environmental change will impact soil biodiversity. It is also clear that some of our knowledge exploring the functionality and relationships of aboveground biota are applicable belowground, however the specific nature of spatial, temporal and organizational structure of soil biodiversity merits a separate line of investigation. Forest ecosystems and notorious for the high levels of difficulties in manipulating environmental factors and for large variation of soil factors. Nevertheless, a combination of experimental and observational (forest monitoring plots) research methods may be able to provide insights into the role of soil biodiversity in ecosystem function and resilience as affected be environmental change.

\section{References}

Altieri, M. A., 1999: The ecological role of biodiversity in agroecosystems. Agriculture, Ecosystems \& Environment, 74:19-31.

Austin, A. T., Yahdjian, L., Stark, J. M., Belnap, J., Porporato, A., Norton, U. et al., 2004: Water pulses and biogeochemical cycles in arid and semiarid ecosystems. Oecologia, 141:221-235.
Bais, H. P., Weir, T. L., Perry, L. G., Gilroy, S.,Vivanco, J. M., 2006: The role of root exudates in rhizosphere interactions with plants and other organisms. Annual Review Plant Biology, 57:233-266.

Bardgett, R. D.,Vad Der Putten, W. H., 2014: Belowground biodiversity and ecosystem functioning. Nature, 515:505-511.

Callaway, R. M.,Maron, J. L., 2006: What have exotic plant invasions taught us over the past 20 years? Trends in Ecology \& Evolution, 21:369-374.

Cardinale, B. J., Duffy, J. E., Gonzalez, A., Hooper, D. U., Perrings, C., Venail, P. et al., 2012: Biodiversity loss and its impact on humanity. Nature, 486:59-67.

Curran, T.J., 2011: Foundations of Ecological Resilience. Austral Ecology, 36:e30-e31.

Decaëns, T., 2010: Macroecological patterns in soil communities. Global Ecology and Biogeography, 19:287-302.

Duveneck, M. J.,Scheller, R. M., 2015: Measuring and managing resistance and resilience under climate change in northern Great Lake forests (USA). Landscape Ecology, 31:669-686.

El Zahar Haichar, F., Marol, C., Berge, O., Rangel-Castro, J. I., Prosser, J. I., Balesdent, J. M. et al., 2008: Plant host habitat and root exudates shape soil bacterial community structure. The ISME journal, 2: 1221-1230.

Elliott, E. T., 1986: Aggregate structure and carbon, nitrogen, and phosphorus in native and cultivated soils. Soil Science Society of America Journal, 50:627-633.

Elmqvist, T., Folke, C., Nyström, M., Peterson, G., Bengtsson, J., Walker, B. et al., 2003: Response diversity, ecosystem change, and resilience. Frontiers in Ecology and the Environment, 1:488-494.

Fedrowitz, K., Koricheva, J., Baker, S. C., Lindenmayer, D. B., Palik, B., Rosenvald, R. et al., 2014: Review: Can retention forestry help conserve biodiversity? A meta-analysis. Journal of Applied Ecology, 51:16691679.

Fierer, N., Jackson, R. B., 2006: The diversity and biogeography of soil bacterial communities. Proceedings of the National Academy of Sciences of the United States of America, 103:626-631.

Fischer, J., Lindenmayer, D. B., Manning, A. D., 2006: Biodiversity, ecosystem function, and resilience: ten guiding principles for commodity production landscapes. Frontiers in Ecology and the Environment, 4:80-86.

Foley, J. A., Ramankutty, N., Brauman, K. A., Cassidy, E. S., Gerber, J. S., Johnston, M. et al., 2011: Solutions for a cultivated planet. Nature, 478:337-342.

Folke, C., Carpenter, S., Walker, B., Scheffer, M., Elmqvist, T., Gunderson, L.,Holling, C. S., 2004: Regime shifts, resilience, and biodiversity in ecosystem management. Annual Review of Ecology, Evolution, and Systems, 35:557-581. 
García-Nieto, A. P., García-Llorente, M., Iniesta-Arandia, I.,Martín-López, B., 2013: Mapping forest ecosystem services: from providing units to beneficiaries. Ecosystem Services, 4:126-138.

Giller, K. E., Beare, M. H., Lavelle, P., Izac, A.-M.,Swift, M. J., 1997: Agricultural intensification, soil biodiversity and agroecosystem function. Applied Soil Ecology, 6:3-16.

Grime, J. P., 1997: Biodiversity and ecosystem function: the debate deepens. Science, 277:1260-1261.

Hamel, C., Hanson, K., Selles, F., Cruz, A. F., Lemke, R., Mcconkey, B. et al., 2006: Seasonal and long-term resource-related variations in soil microbial communities in wheat-based rotations of the Canadian prairie. Soil Biology and Biochemistry, 38:2104-2116.

Isbell, F., Craven, D., Connolly, J., Loreau, M., Schmid, B., Beierkuhnlein, C. et al., 2015: Biodiversity increases the resistance of ecosystem productivity to climate extremes. Nature, 526:574-577.

Langenheder, S., Prosser, J. I., 2008: Resource availability influences the diversity of a functional group of heterotrophic soil bacteria. Environmental Microbiology, 10:2245-2256.

Lauber, C. L., Ramirez, K. S., Aanderud, Z., Lennon, J., Fierer, N., 2013: Temporal variability in soil microbial communities across land-use types. The ISME Journal, 7:1641-1650.

Lindenmayer, D. B., Franklin, J. F., Lohmus, A., Baker, S. C., Bauhus, J., Beese, W. et al., 2012: A major shift to the retention approach for forestry can help resolve some global forest sustainability issues. Conservation Letters, 5:421-431.

Mace, G. M., Norris, K.,Fitter, A. H., 2012: Biodiversity and ecosystem services: a multilayered relationship. Trends in Ecology \& Evolution, 27:19-26.

Messier, C., Puettmann, K., Chazdon, R., Andersson, K. P., Angers, V.A., Brotons, L. et al., 2015: From management to stewardship: viewing forests as complex adaptive systems in an uncertain world. Conservation Letters, 8:368-377.

Mikola, J.,Setälä, H., 1998: Productivity and trophiclevel biomasses in a microbial-based soil food web. Oikos, p. 158-168.

Mori, A. S., Lertzman, K. P.,Gustafsson, L., 2017: Biodiversity and ecosystem services in forest ecosystems: a research agenda for applied forest ecology. Journal of Applied Ecology, 54:12-27.

Myers, N., Mittermeier, R. A., Mittermeier, C. G., Da Fonseca, G. A., Kent, J., 2000: Biodiversity hotspots for conservation priorities. Nature, 403:853-858.

Neutel, A.-M., Heesterbeek, J. A.,De Ruiter, P. C., 2002: Stability in real food webs: weak links in long loops. Science, 296:1120-1123.

Neutel, A.-M., Heesterbeek, J. A., Van De Koppel, J., Hoenderboom, G., Vos, A., Kaldeway, C., Berendse, F. et al., 2007: Reconciling complexity with stability in naturally assembling food webs. Nature, 449:599602.
Newbold, T., Scharlemann, J. P., Butchart, S. H., Şekercioğlu, Ç. H., Joppa, L., Alkemade, R. et al., 2014: Functional traits, land-use change and the structure of present and future bird communities in tropical forests. Global ecology and biogeography, 23:1073-1084.

Oliver, T. H., Heard, M. S., Isaac, N. J., Roy, D. B., Procter, D., Eigenbrod, F. et al., 2015: Biodiversity and resilience of ecosystem functions. Trends in Ecology \& Evolution, 30:673-684.

Öpik, M., Moora, M., Liira, J.,Zobel, M., 2006: Composition of root-colonizing arbuscular mycorrhizal fungal communities in different ecosystems around the globe. Journal of Ecology, 94:778-790.

Pasari, J. R., Levi, T., Zavaleta, E. S.,Tilman, D., 2013: Several scales of biodiversity affect ecosystem multifunctionality. Proceedings of the National Academy of Sciences, 110:10219-10222.

Rasche, F., Knapp, D., Kaiser, C., Koranda, M., Kitzler, B., Zechmeister-Boltenstern, S. et al., 2011: Seasonality and resource availability control bacterial and archaeal communities in soils of a temperate beech forest. The ISME Journal, 5:389-402.

Reinhart, K. O.,Callaway, R. M., 2006: Soil biota and invasive plants. New Phytologist, 170:445-457.

Richardson Dodge, S., 2000: An even more humongous fungus. Pacific Northwest Research Station, US Forest Service.

Rooney, N., Mccann, K., Gellner, G.,Moore, J. C., 2006: Structural asymmetry and the stability of diverse food webs. Nature, 442:265-269.

Scherer-Lorenzen, M., 2014: The functional role of biodiversity in the context of global change. Forests and Global Change, p. 195-237.

Schröter, D., Cramer, W., Leemans, R., Prentice, I. C., Araújo, M. B., Arnell, N. W. et al., 2005: Ecosystem service supply and vulnerability to global change in Europe. Science, 310:1333-1337.

Schulze, E.-D., Mooney, H.A., 1994:Ecosystem function of biodiversity: a summary, Biodiversity and ecosystem function. Springer, p. 497-510.

Smith, B. D., Zeder, M.A., 2013: The onset of the Anthropocene. Anthropocene, 4:8-13.

Standish, R. J., Hobbs, R. J., Mayfield, M. M., Bestelmeyer, B. T., Suding, K. N., Battaglia, L. L. et al., 2014: Resilience in ecology: Abstraction, distraction, or where the action is? Biological Conservation, 177:43-51.

Stark, J. M.,Firestone, M. K., 1995: Mechanisms for soil moisture effects on activity of nitrifying bacteria. Applied and Environmental Microbiology, 61:218-221.

Strickland, M. S., Lauber, C., Fierer, N.,Bradford, M. A., 2009: Testing the functional significance of microbial community composition. Ecology, 90:441-451. 
Tedersoo, L., Bahram, M., Toots, M., Diedhiou, A. G., Henkel, T. W., Kjøller, R. et al., 2012: Towards global patterns in the diversity and community structure of ectomycorrhizal fungi. Molecular Ecology, 21:4160-4170.

Turbé, A., De Toni, A., Benito, P., Lavelle, P., Lavelle, P., Camacho, N. R. et al., 2010: Soil biodiversity: functions, threats and tools for policy makers.

Wardle, D. A., Bardgett, R. D., Klironomos, J. N., Setälä, H., Van Der Putten, W. H.,Wall, D. H., 2004: Ecological linkages between aboveground and belowground biota. Science, 304:1629-1633.
Wilcove, D. S., Giam, X., Edwards, D. P., Fisher, B.,Koh, L. P., 2013: Navjot's nightmare revisited: logging, agriculture, and biodiversity in Southeast Asia. Trends in Ecology \& Evolution, 28:531-540.

Worm, B.,Duffy, J. E., 2003: Biodiversity, productivity and stability in real food webs. Trends in Ecology \& Evolution, 18:628-632.

Yachi, S., Loreau, M., 1999: Biodiversity and ecosystem productivity in a fluctuating environment: the insurance hypothesis. Proceedings of the National Academy of Sciences, 96:1463-1468. 